\title{
Differential diagnosis and clinical management of periapical radiopaque/hyperdense jaw lesions
}

\author{
Brunno Santos Freitas SILVA ${ }^{(a)}$ \\ Mike Reis BUENO(b) \\ Fernanda P. YAMAMOTO-SILVA ${ }^{\text {(c) }}$ \\ Ricardo Santiago GOMEZ(d) \\ Ove Andreas PETERS(e) \\ Carlos ESTRELA(c) \\ (a) Universidade de Anápolis, School of \\ Dentistry, Department of Oral Diagnosis, \\ Anápolis, GO, Brazil. \\ (b) Universidade de Cuiabá - UNIC, School \\ of Dentistry, Department of Stomatology, \\ University of Cuiabá, Cuibá, MT, Brazil \\ (c) Universidade Federal de Goiás - UFG, \\ School of Dentistry, Department of \\ Stomatologic Sciences, Goiânia, GO, Brazil. \\ (d) Universidade Federal de Minas Gerias - \\ UFMG, School of Dentistry, Department of \\ Oral Surgery and Pathology, Belo Horizonte, \\ MG, Brazil. \\ (e) University of the Pacific, Arthur A. Dugoni \\ School of Dentistry, Department of \\ Endodontics, San Francisco, CA, United \\ States of America.
}

Declaration of Interest: The authors certify that they have no commercial or associative interest that represents a conflict of interest in connection with the manuscript.

\section{Corresponding Author:}

Carlos Estrela

E-mail: estrela3@terra.com.br

https://doi.org/10.1590/1807-3107BOR-2017.vol31.0052

Submitted: Mar 03,2017

Accepted for publication: Apr 27, 2017

Last revision: May 21, 2017

\begin{abstract}
Great attention has been given to the study of radiolucent periapical lesions to avert possible misdiagnosis of apical periodontitis associated with certain radiolucent non-endodontic lesions. However, there are a significant number of radiopaque lesions found in the periapical region, which could be equally relevant to endodontic practice. The diagnosis and management of these radiopaque/hyperdense lesions could be challenging to the endodontist. These bone alterations could be neoplastic, dysplastic or of metabolic origin. In the context of the more widespread use of cone-beam CT, a detailed review of radiopaque inflammatory and non-inflammatory lesions is timely and may aid clinicians perform a differential diagnosis of these lesions. Distinguishing between inflammatory and non-inflammatory lesions simplifies diagnosis and consequently aids in choosing the correct therapeutic regimen. This review discusses the literature regarding the clinical, radiographic, histological and management aspects of radiopaque/hyperdense lesions, and illustrates the differential diagnoses of these lesions.
\end{abstract}

Keywords: Periapical Peridodontitis; Diagnosis, Differential.

\section{Introduction}

The decision-making process for a therapeutic protocol in root canal infection must be based on an efficient diagnosis. ${ }^{1}$ Dental granuloma, radicular cyst and periapical abscess represent periapical changes of frequent occurrence. ${ }^{2}$ The progressive stages of inflammation and periapical bone structure resulting in resorption are identified as exhibiting radiolucency on radiographic exams. ${ }^{3}$ However, radiopaque lesions are also identified near the apex of the teeth and should receive attention, because they may be of endodontic or non-endodontic origin. ${ }^{4}$ Osteoblastic and osteoclastic activity has been associated with low-grade chronic periapical inflammation. ${ }^{5}$

Imaging exams could produce essential information about margination, the relationship between the lesion and adjacent teeth, and the internal content of the lesion, especially in cases containing calcified deposits. ${ }^{6}$.Great attention has been given to the study of radiolucent periapical lesions to avert possible misdiagnosis of apical periodontitis (AP) associated with certain radiolucent non-endodontic lesions. ${ }^{4,7}$ However, there are 
a significant number of radiopaque lesions that are found in the periapical region, which could be equally relevant to endodontic practice. $89,10,11$

Endodontic diagnosis is dependent on clinical and radiographic examinations. Periapical radiographs and cone beam computed tomography (CBCT) images represent important exams in the detection and diagnosis of inflammatory, dysplastic and neoplastic periapical diseases. ${ }^{12,13,14}$ For many clinicians, the diagnosis and management of radiopaque/hyperdense lesions could be extremely challenging. In 1985, Bender and Mori discussed the diagnostic considerations of certain periapical and periodontal radiopacities of endodontic and periodontal origin..$^{15} \mathrm{~A}$ detailed review of radiopaque inflammatory and non-inflammatory lesions could be opportune and aid the endodontist and clinician in carrying out a differential diagnosis of these lesions.

This study reviewed the literature regarding the clinical, radiographic, histological and management aspects of radiopaque/hyperdense lesions, and discusses the differential diagnoses of these lesions.

\section{Methodology}

In the present study, a search was performed in the PubMed online database to identify the available studies, reviews and case reports on radiopaque/hyperdense inflammatory and non-inflammatory lesions of the jaws, particularly those that could occur in the periapical region. The search included only articles in the following areas, published in English and in indexed dental or medical journals, addressing information concerning radiopaque lesions: etiology; clinical aspects; radiographic characteristics; histological characteristics; and management. An additional hand search was performed in the following journals: Journal of Endodontics; Oral Surgery, Oral Medicine, Oral Pathology, Oral Radiology; Oral Oncology; International Endodontic Journal; and Head and Neck Pathology. The selected articles were included only when judged to contain relevant and pertinent information by the authors of this study, representing different areas of dentistry (endodontics - CE and OAP; oral pathology - BSFS and RSG; oral radiology - MRB and FPYS; and oral medicine - FPYS). The World Health Organization (WHO) Classification of Head and Neck Tumours ${ }^{16}$ and the Oral and Maxillofacial Pathology textbook published by Neville et al. ${ }^{2}$ were included in this study due to their relevance in the area of oral pathology, and served as a parameter in cases of any divergence in the information collected in the selected articles or lack of pertinent information on certain diseases in the literature. A total of 22 entities were described in the pertinent literature (Table). Broadly, disease entities may be inflammatory, non-inflammatory, neoplastic and metabolic in nature. The following review details clinical and radiographic features of specific diseases in the four groups.

\section{Results}

\section{Inflammatory lesions}

\section{Reactional osteogenesis}

Reactional osteogenesis ( $\mathrm{RO}$ ) has been recently described as an asymptomatic, localized radiopaque lesion occurring in the maxillary sinus and associated to a molar apex compromised by secondary root canal infection. It is believed that $\mathrm{RO}$ is a response of the sinus mucosa to low-intensity and prolonged inflammatory aggression from an infected root canal, which results in the production of new bone on the superficial cortical of the maxillary sinus. ${ }^{12} \mathrm{RO}$ is considered an incidental radiographic finding characterized as an ill-defined, dome-shaped, radiopaque thickening that resembles a retention pseudocyst in conventional radiographs. In CBCT images, this condition presents as a hyperdense, well-defined lesion, with a shape varying from irregular to round to ovoid (Figure 1, A-C). Except for the four cases described by Estrela et al., ${ }^{12}$ there are no other reports or epidemiological studies about this entity. In the study mentioned, all four cases were detected in female patients between the fifth and seventh decades of life. Histologically, reactional osteogenesis presents bone tissue with distinct stages of maturation, concentric layers of lamellae and organized haversian systems, and may also show mature tissue, marrow and inflammatory cell infiltrate. From a therapeutic point of view, the treatment should focus on eradicating the root canal infection responsible for the maxillary sinus inflammation, and on eliminating the bone reaction; however, if this does not resolve the apical infection, surgical treatment is recommended. 


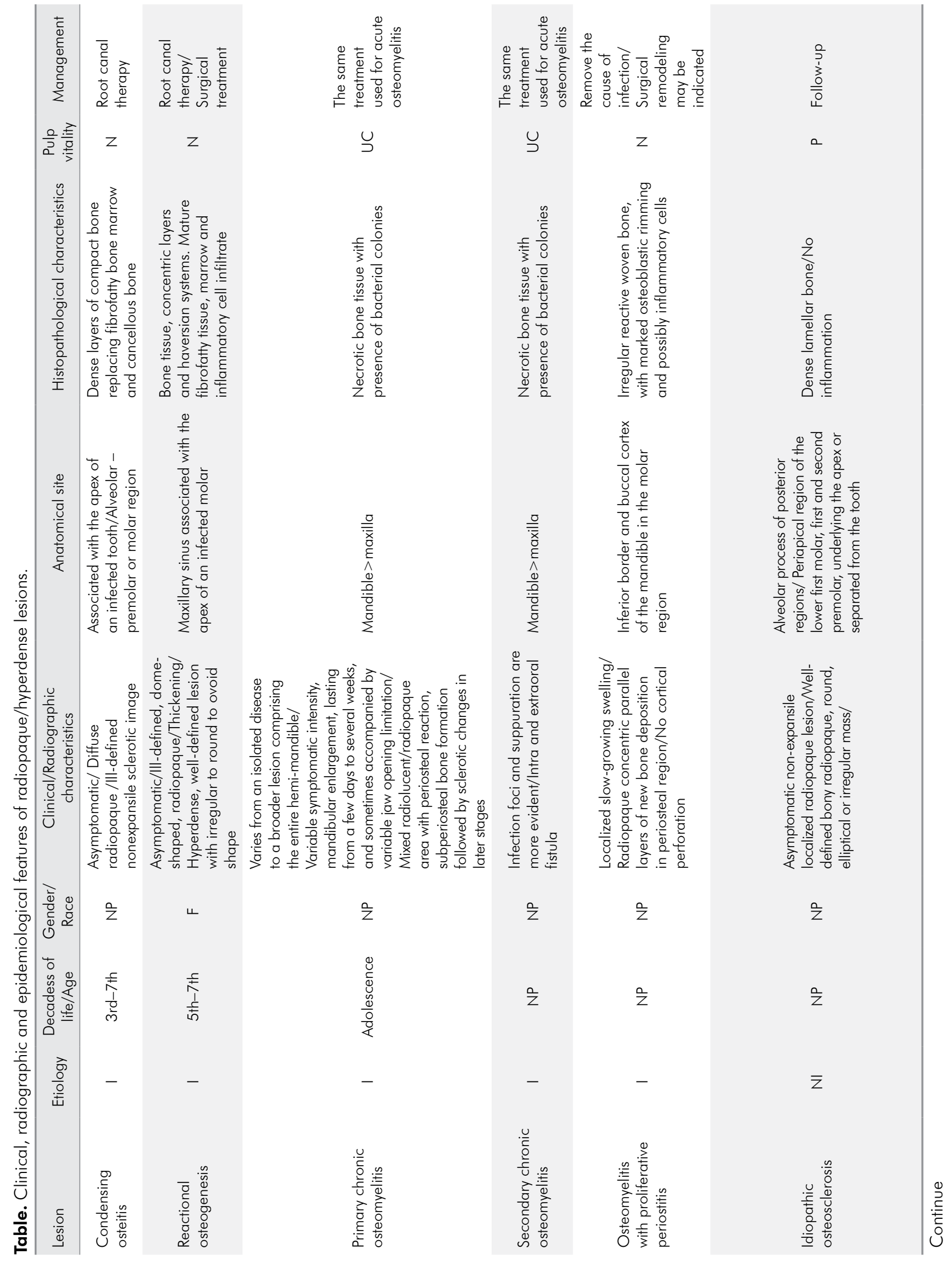




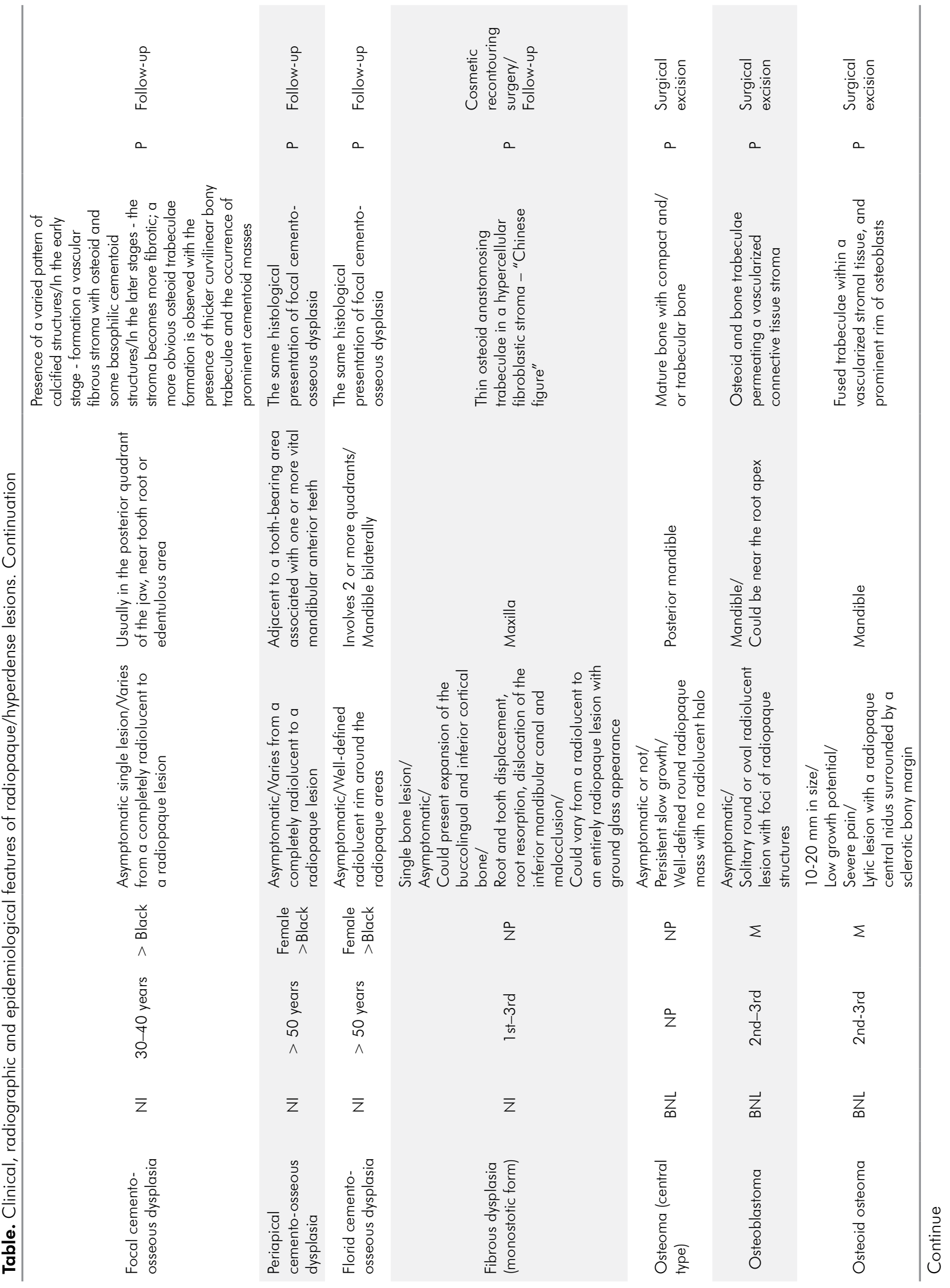




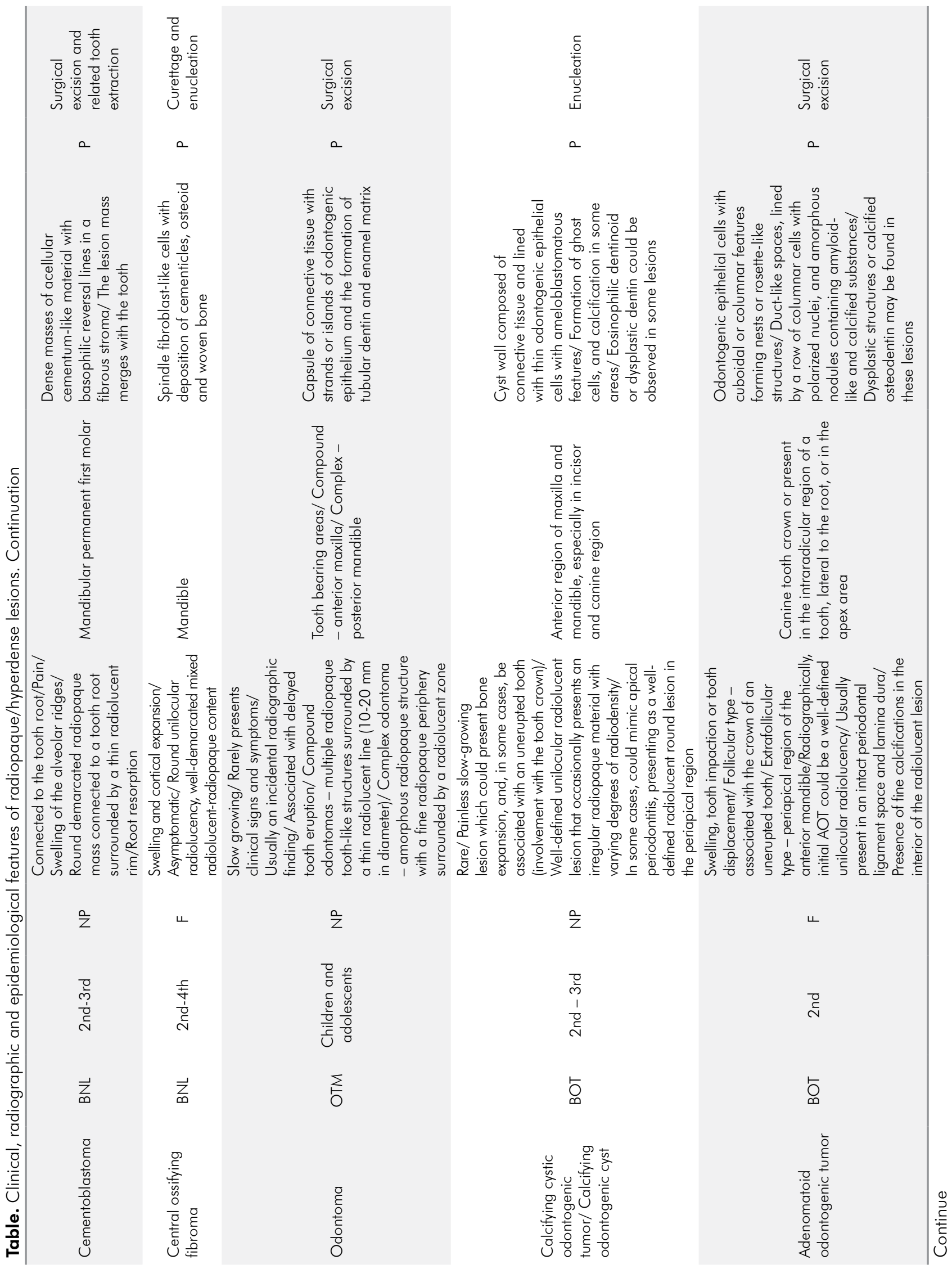




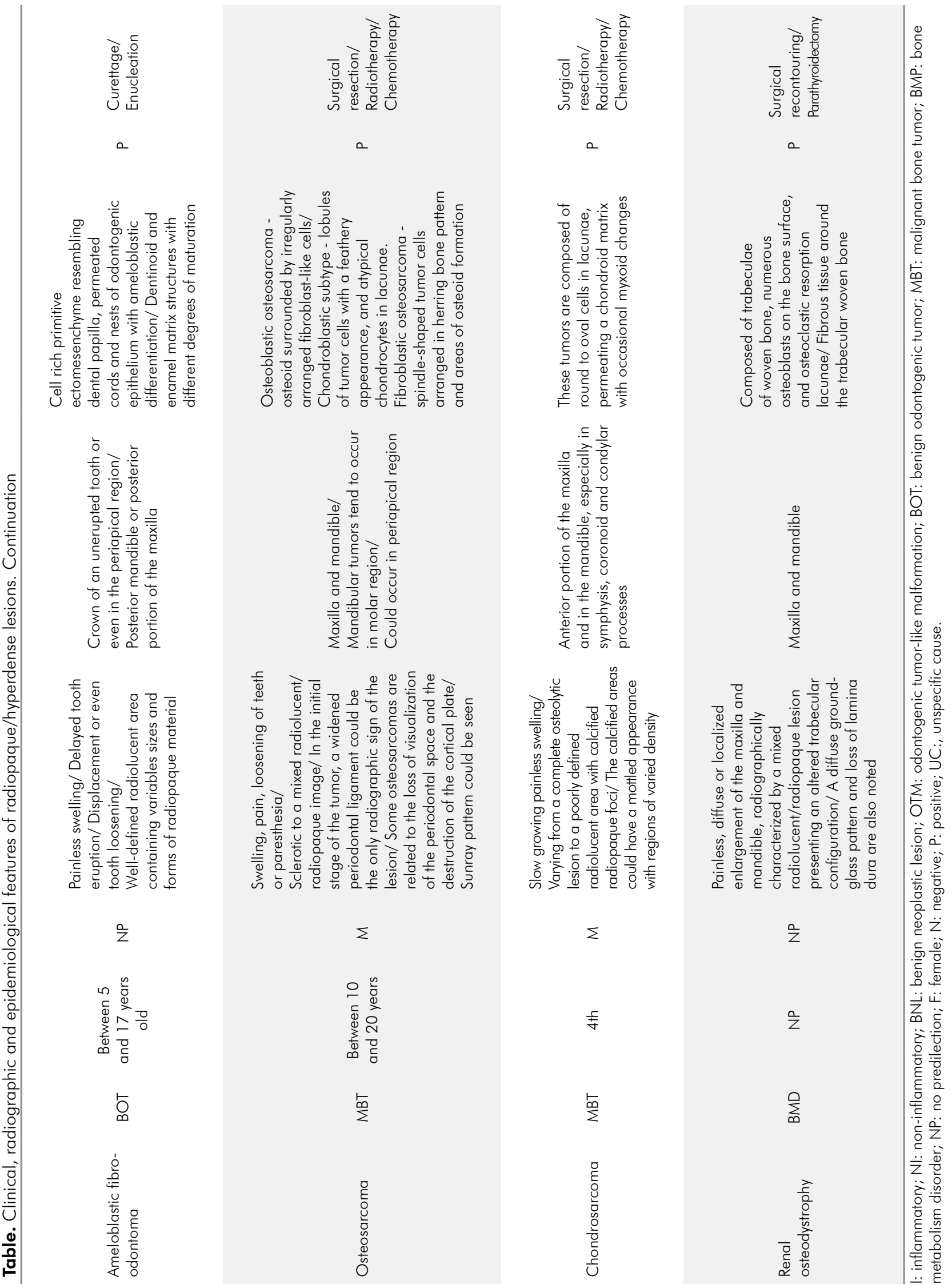




\section{Condensing osteitis (focal sclerosing} osteomyelitis)

Condensing osteitis (CO), also known as focal sclerosing osteomyelitis, is an asymptomatic, pathological, persistent change in osseous structure presumed to be the response to a long-standing and low-grade inflammatory stimulus from an inflamed or necrotic pulp. ${ }^{17} \mathrm{CO}$ appears in periapical radiographs as a diffuse radiopaque bone lesion in the alveolar process, primarily associated with a mandibular premolar or molar apex, or at a tooth extraction site. This condition is seen as affecting a tooth with clinical indications of pulp disease, such as deep caries or large restorations. ${ }^{18,19} \mathrm{CO}$ eventually may emerge adjacent to radiolucent inflammatory periapical lesions (granuloma, cyst and abscess) (Figure 1, D), or in an enlarged periodontal ligament space ${ }^{6}$. In CBCT exams, $\mathrm{CO}$ is observed as an ill-defined non-expanding sclerotic image associated with an infected tooth (Figure 1, E). Despite the considerable variation in the epidemiology of $\mathrm{CO}$ presented in the literature, apparently, these lesions are detected more often between the third to seventh decades of life, with no distinction between male and female genders. ${ }^{20}$ Biopsy is not required for $\mathrm{CO}$ diagnosis, and its histological pattern has only recently been described. CO microscopically presents dense layers of compact bone replacing bone marrow and cancellous bone. Fibrosis and inflammation are occasionally seen in the bone marrow region. ${ }^{18}$ The diagnosis of condensing osteitis is based solely on clinical and radiographic characteristics, and the treatment of choice is root canal treatment. ${ }^{19}$

\section{Osteomyelitis of the jaw}

Osteomyelitis is defined as an inflammatory condition of the medullary and cancellous portion of the bone, which spreads to the haversian systems and eventually comprises the periosteum of the affected area. ${ }^{20}$ Osteomyelitis predominantly affects the mandible, with just a small number of cases affecting the maxilla, probably due to its rich vascularity. ${ }^{6}$ In most cases, odontogenic infection etiology is evident; however, in some cases, the causal factor of osteomyelitis is not recognizable. ${ }^{21}$ The significant clinical/pathological variability of osteomyelitis
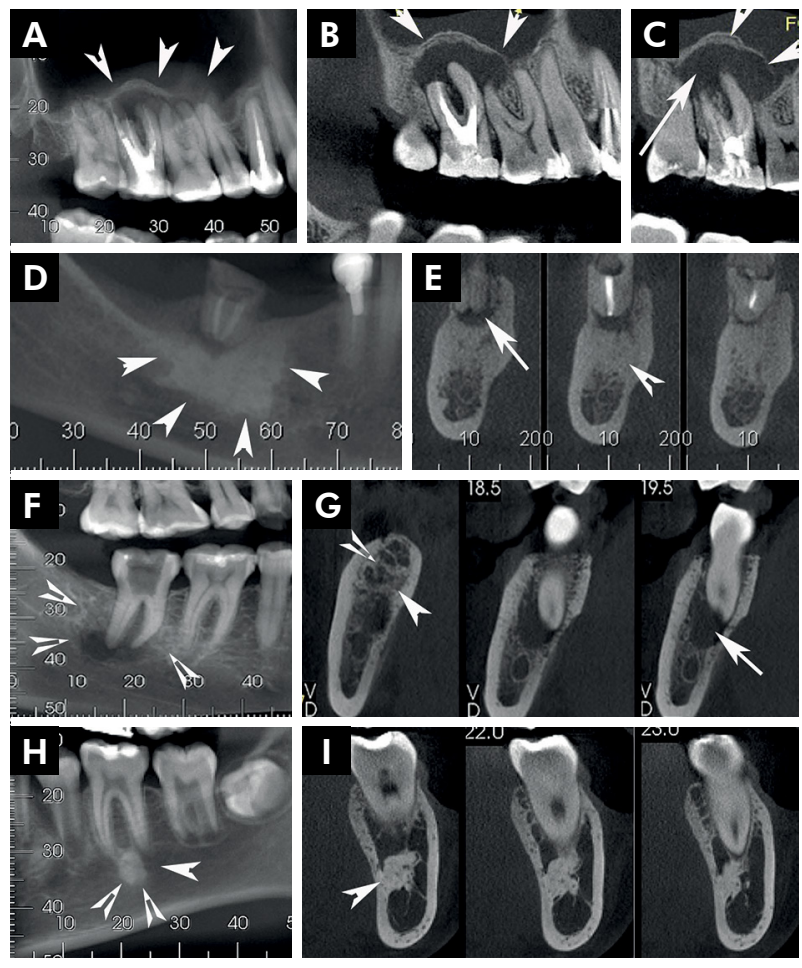

Figure 1. Reactional osteogenesis: Cone beam computed tomography $(\mathrm{CBCT})$ images showing a hyperdense irregularly shaped structure (arrow head) in the right maxillary sinus (A-B), associated with an inflammatory hypodense periapical lesion (arrow) (C). Condensing osteitis (CO): CBCT presenting a diffuse hyperdense lesion in the apex of a mandibular molar (arrowhead) (D), adjacent to an inflammatory periapical lesion (arrow) (E). Chronic osteomyelitis: CBCT views show a mixed hypodense/hyperdense lesion (F) with evident sclerotic changes (arrow head) in the periapical region of a mandibular right molar, and with the presence of an inflammatory hypodense periapical lesion (arrow) (G). Idiopathic osteosclerosis (IO): In CBCT images, it is observed as a hyperdense round lesion (arrowhead) located under the apex of an apparently non-infected tooth $(H)$. $1 O$ lesion is clearly separated from the root of the adjacent tooth by a visible periodontal membrane (I).

of the jaw has led to several classifications being proposed for this disease. Among all the stages of osteomyelitis described in this study, we focused particularly on describing those with the potential of inducing radiopaque changes in imaging exams.

Chronic osteomyelitis (COS) represents a bone infection that endures at least one month. ${ }^{22,23,24} \mathrm{Chronic}$ osteomyelitis could present an unspecific cause, and varies clinically from an isolated disease limited to part of the mandible to a broader lesion comprising the entire hemi-mandible. ${ }^{23}$ Chronic osteomyelitis also presents 
variable symptomatic intensity, lasting from a few days to several weeks, and is sometimes accompanied by a variable jaw opening limitation. In this stage, the patient does not present fever, leukocytosis or suppuration, but merely a mandibular enlargement without evident soft tissue involvement. Chronic osteomyelitis affects all age groups; however, it has been observed in an initial incidence peak in adolescence, and in a second peak after 50 years of age. In some cases, chronic osteomyelitis infectious foci and suppuration are more evident, together with intra- and extraoral fistula formation and overlying soft tissue involvement. Chronic osteomyelitis could present sequestration and pathologic fractures at some stage..$^{21}$ In chronic osteomyelitis, the imaging exams are important to rule out malignant tumors; however, biopsy is indicated when radiographs cannot confirm the inflammatory nature of the lesion. ${ }^{23}$ In its initial stages, chronic osteomyelitis shows a mixed radiolucent/radiopaque area with various degrees of periosteal reaction, and subperiosteal bone formation, usually followed by sclerotic changes in later stages (Figure 1, F-G). ${ }^{23}$ In acute osteomyelitis and chronic osteomyelitis, the therapeutic regimen consists of eradication of the causative microbial agent with administration of broad-spectrum antibiotics, surgical removal of infected teeth, surgical debridement of any infected bone, or sequestrectomy of any necrotic bone fragments ${ }^{26}$. Decortication of cortical plates to access the infected medullary bone, or surgical resection, is indicated in treating chronic refractory osteomyelitis. ${ }^{24}$

Osteomyelitis with proliferative periostitis (OSPP) is a kind of chronic osteomyelitis that presents an inflammatory reaction, which results in periosteal new bone formation. This condition has been described using several terms, including proliferative periostitis, periostitis ossificans, and Garre's osteomyelitis. Although some studies have considered OSPP as synonymous to Garre's osteomyelitis, the latter could be defined as acute osteomyelitis with inflammatory periosteal new bone formation. OSPP is associated with an odontogenic infection, usually of endodontic origin, and generally presents a localized, slow-growing swelling in the inferior border and buccal cortex of the mandible in the molar region. ${ }^{27}$ In radiographic exams, OSPP presents radiopaque concentric parallel layers of new bone deposition in the periosteal region (onion skin appearance) with no cortical perforation. Histological findings of all types of COS mainly consist of irregular, reactive woven bone, or sclerotic bone with occluded haversian systems and varying degrees of marrow fibrosis. Marked osteoblastic rimming and inflammatory cells (acute and chronic cells) may be present in chronic osteomyelitis specimens. ${ }^{23}$ OSPP may be treated by removing the cause of the infection, which may involve endodontic treatment or surgical removal. In general, resolution of the infection promotes bone remodeling. If lamellar bone growth is extensive, surgical remodeling may be indicated. ${ }^{27}$

\section{Non-inflammatory lesions}

\section{Idiopathic osteosclerosis}

Idiopathic osteosclerosis $(\mathrm{IO})$ is an asymptomatic, nonexpansile, localized radiopaque lesion observed in the alveolar process in posterior regions without any obvious etiological agent. ${ }^{28}$ In terms of frequency, IO more frequently involves the periapical region of the lower first molar, followed by the mandibular first and second premolars. ${ }^{29}$ IO lesions may be observed as follows: superimposed over the root of a tooth, with a less visible periodontal membrane; underlying the apex of a tooth separated from the root, with a visible periodontal membrane; or separated from a tooth more closely to the inferior border. ${ }^{30}$ The radiographic characteristic of IO includes a well-defined bony radiopaque/hyperdense lesion, which could be manifest as a round, elliptical or irregular mass with a ground-glass appearance (Figure 1, G-H). ${ }^{28,31}$ The diagnosis of IO is frequently based on radiographic and clinical findings such as radiopaque areas located subjacent to apices of asymptomatic sound teeth, or with small restorations, without any other evident cause. ${ }^{30}$ A longstanding observational study indicated that this condition is very stable, and that there is no apparent need for any intervention either in IO or in the tooth near the lesion. ${ }^{28}$ Although biopsy is not needed, the microscopic picture of IO is characterized by a dense lamellar bone and small marrow channels without inflammatory cell infiltration. 


\section{Cemento-osseous dysplasia}

Cemento-osseous dysplasia (COD) is the most common fibro-osseous lesion found in the jaws. COD represents a group of benign lesions of unknown etiology characterized by the substitution of normal bone by fibrous tissue with newly formed mineralized structures. ${ }^{32}$ These lesions vary from completely radiolucent to radiopaque, depending on the maturational stage of the disease. COD has been divided into three subtypes based on its radiographic presentation: focal cemento-osseous dysplasia, periapical cemento-osseous dysplasia, and florid cemento-osseous dysplasia. Usually, the three subtypes of COD are accidental findings in routine radiographs. ${ }^{16}$

Focal COD is an asymptomatic single lesion that usually occurs in the posterior quadrant of the jaw, either near the root of a tooth or in an edentulous area. ${ }^{18}$ This lesion is more prevalent in the posterior mandible of females with a mean age between thirty and forty years. There is a relative predilection among black patients. ${ }^{33}$ Periapical COD is also an asymptomatic lesion that occurs adjacent to a tooth-bearing area associated with one or more vital mandibular anterior teeth. Usually, this condition affects middle-age females, and also has a strong predilection for black patients. ${ }^{34}$ When COD involves 2 or more quadrants of the jaw, this condition is called florid COD. Florid COD is a lesional tissue that usually affects the mandible bilaterally, and, in some instances, involves the maxilla, affecting middle-age black females. However other age, racial and gender groups may be affected. ${ }^{18}$

In general, COD tends to present different radiographic phases that vary from an entirely radiolucent lesion to a mixed or radiopaque lesion near the apices of mandibular teeth, or at a tooth extraction site. The radiolucent lesions resemble periapical endodontic infections; however, the tooth responds positively to the pulp vitality tests. The mixed and radiopaque lesions are round in shape, with a well-defined radiolucent rim around the radiopaque areas, and with no evident signs of the lesions merging with the root of the tooth (Figure 2, A-D). ${ }^{18}$

The histopathological characteristics of COD comprise the presence of varied patterns of calcified
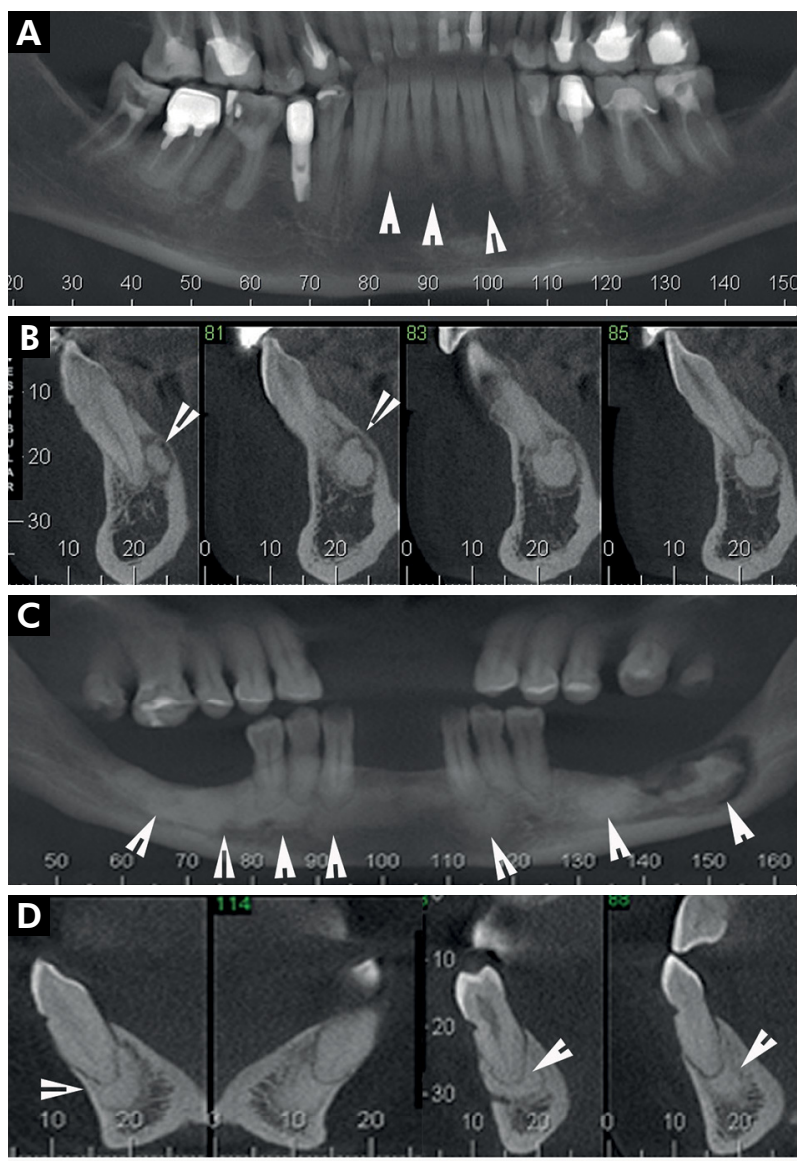

Figure 2. Periapical cemento-osseous dysplasia (periapical COD): Panoramic images showing hyperdense round lesions in the periapical region of a mandibular anterior sound tooth (arrowhead) (A). Cross-sectional images showing periapical COD lesions markedly separated from the adjacent normal bone and also separated from the root of the anterior tooth (arrowhead) (B). Florid COD: In CBCT images, hyperdense multiple lesions are observed that involve the mandible bilaterally (arrow head) and bone sequestration in left mandible (arrow) (C). In (D), hyperdense elliptical lesions are seen clearly separated from the root of a mandibular tooth (arrowhead).

structures. In the early stage of COD formation, a vascular fibrous stroma with osteoid and some basophilic cementoid structures can be observed. In the later stages of the disease, the stroma becomes more fibrotic, and a more distinct osteoid trabeculae formation is observed with the presence of thicker curvilinear bony trabeculae, and possible occurrence of prominent cementoid masses. When the clinical and radiographic characteristics of COD are clearly identified, there is no need for biopsy or any surgical treatment. ${ }^{18}$ However, a periodic radiographic 
follow-up is needed to validate COD diagnosis ${ }^{34}$ and also to prevent odontogenic infections in the teeth overlying any lesional tissue. Since COD is represented by an avascular and dysplastic bone, odontogenic infections could result in widespread contamination developing into osteomyelitis and bone sequestration (Figure 2, C). ${ }^{18}$

\section{Fibrous dysplasia}

Fibrous dysplasia (FD) is a benign developmental disorder characterized by a dysplastic process of altered osteogenesis with subsequent substitution of normal bone by fibrous tissue that undergoes abnormal mineralization. Its pathogenesis is associated with a mutation of the gene that encodes the $G$ protein alpha-subunit (Gs-alpha), disturbing the guanosine triphosphatase function and increasing levels of cyclic adenosine mono-phospate (cAMP), which stimulate endocrine receptors. It is believed that an increase in intracellular cAMP levels in bone marrow osteoprogenitor cells may affect the proliferation and differentiation of preosteoblasts ${ }^{18,35}$. FD may present as a single bone lesion, known as the monostotic form, or multiple bone lesions, called the polyostotic form. The polyostotic form is less common and could be associated with McCunee-Albright's Syndrome, characterized by hormonal changes, precocious puberty, skin pigmentation and other endocrine disturbances. ${ }^{36}$ The monostotic form represents the majority of FD cases and could affect the craniofacial bones, including the maxilla and the mandible, considering that the maxilla is deemed the more often affected jaw site in comparison with the mandible. These lesions do not present gender or racial predilection, and are identified mainly as occurring in the first to third decades of life. Monostotic FD is clinically characterized as an asymptomatic bone swelling that could result in an expansion of the buccolingual and inferior cortical bone, obliteration of the maxillary sinus, root and tooth displacement, root resorption, dislocation of the inferior mandibular canal, ${ }^{35}$ and malocclusion. ${ }^{37}$ Radiographically, FD could vary from radiolucent to an entirely radiopaque lesion, with the majority of cases presenting mixed and radiopaque images that merge into the normal bone margins, assuming a ground-glass appearance (Figure 3, A and C). Additionally, conventional radiographs may show
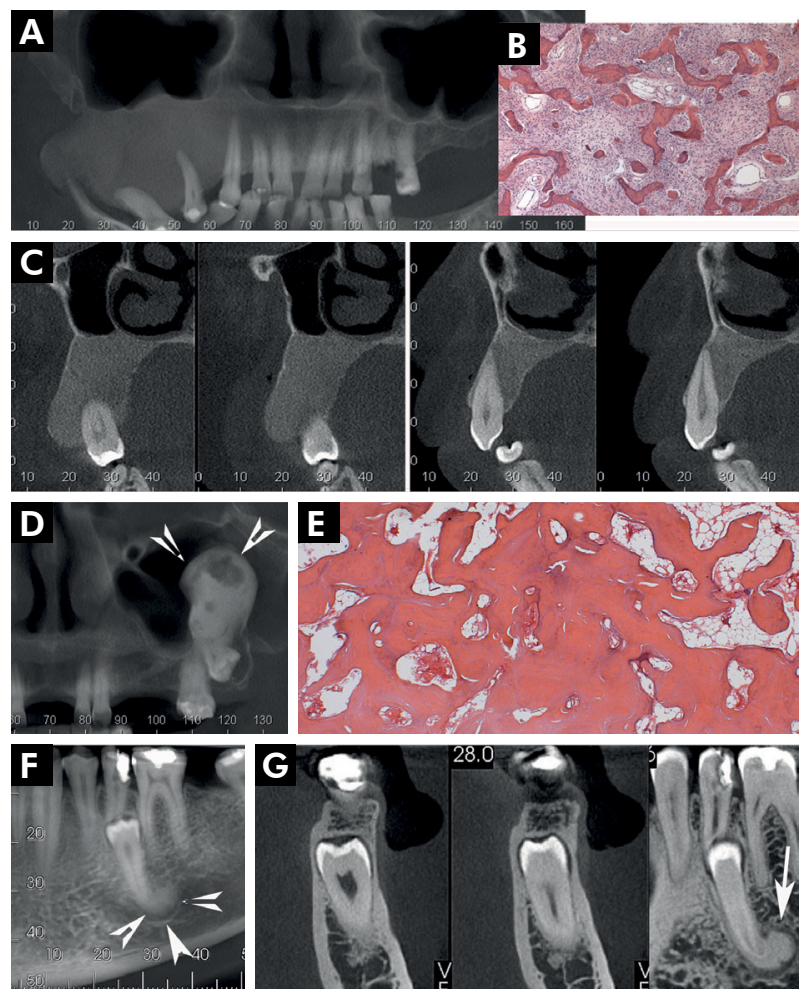

Figure 3. Fibrous dysplasia: CBCT views showing a homogeneous hyperdense lesion in the right maxilla merging into the normal bone margins, and having a ground-glass appearance (A). Craniocaudal expansion and tooth displacement can also be observed (A). Histologically, FD presenting thin osteoid trabeculae with "Chinese-figure" characteristics in a hypercellular fibroblastic stroma (B). In cross-sectional views, it is observed as a narrowing of periodontal ligament space and ill-defined lamina dura of the affected teeth (C). Central osteoma: Panoramic image shows a well-defined round hyperdense mass in the maxillary sinus, associated with the apex of a maxillary tooth (arrow head) (D). Histopathological examination revealing mature, compact and trabecular bones with sparse fibrous-adipose tissue (E). Cementoblastoma: CBCT images showing a well-defined hyperdense round lesion attached to the root of supernumerary mandibular tooth (arrow head) $(F)$ with a surrounding hypodense rim (arrow) (G).

narrowing of periodontal ligament space and ill-defined lamina dura mixed with the lesional bone. ${ }^{2}$ Biopsy is needed to determine FD; however, the clinical and radiographic features, together with the microscopic characteristics, are essential for FD diagnosis. ${ }^{18}$ Because of the clinical and histological similarity of FD to some other benign fibro-osseous lesions, GNAS mutational analysis could be an important adjunct exam for its diagnosis. ${ }^{38}$ 
Histopathological aspects of FD include marked osteogenesis represented by thin osteoid anastomosing trabeculae in a hypercellular fibroblastic stroma. A rim of osteoblasts could be observed adjacent to the trabecula. In advanced stages, the osteoid trabeculae thicken and assume "Chinese figure" characteristics (Figure 3, B). In most instances, the main modalities for managing FD cases are conservative surgical treatment involving cosmetic recontouring surgery, usually after the patient attains his full growth peak, and follow-up; however, new growth may occasionally occur, albeit slow. ${ }^{2,18}$

\section{Benign neoplastic lesions}

\section{Osteoma}

Osteoma is a benign neoplasm composed of mature bone structures with characteristics of cancellous or compact bone. Osteomas may occur throughout the skeleton and even in the epidermis, dermis ${ }^{39}$ and muscles. ${ }^{40}$ However, these tumors are more frequently found in craniofacial bones, including the mandible and maxilla. Apparently, three forms of osteoma have been documented: central osteoma, arising from the endosteum; peripheral osteoma, derived from the periosteum; and extraskeletal soft-tissue osteoma. In cases of multiple osteomas of the jaws, Gardner's Syndrome should be investigated. The majority of solitary cases involving thejawbones are of the peripheral type ${ }^{41}$ predominantly affecting the posterior mandible and the condyle. ${ }^{5}$ Although the solitary central osteoma is rare, some of its characteristics are well described. It seems to be a persistent, slow-growth expansive lesion more frequently found in the mandible, mainly in the premolar region, and may or may not be asymptomatic. ${ }^{41}$ In some instances, central osteomas are not related to a tooth; however, there is evidence of central osteomas associated with root displacement or root resorption. ${ }^{42}$ Central osteoma radiographically presents as a round radiopaque mass with well-defined borders, and with apparently no radiolucent halo between the lesion and the normal bone (Figure 3, D). ${ }^{5}$ The three types of osteomas present the same histological characteristics, comprising the presence of mature bone with compact lamella or/and trabecular bone with sparse channels of fibrovascular tissue (Figure $3, \mathrm{E})^{2}$
Because central osteoma resembles other bone lesions, the final diagnosis should be based on the association of the histological findings, radiographic findings and the presence of evident growth, expansion and displacement of the teeth. ${ }^{41}$ In suspected cases, biopsy is needed, and after the diagnosis is confirmed, surgical excision is recommended. Recurrences after surgical treatment are rare. ${ }^{42}$

\section{Osteoblastoma}

Osteoblastomas are benign, slow-growing bone tumors that account for approximately $1 \%$ of all primary bone tumors. ${ }^{43}$ Most of these tumors are diagnosed in the second and third decades of life, and are frequently seen in the axial skeleton; the mandible is the second most common location. Although osteoblastomas are prevalent in the mandible, the maxilla may also be affected. In general, osteoblastomas are centrally located in the bone; however, some periosteal lesions have also been reported. Apparently, osteoblastomas have a male predilection; however, this gender preference could vary among different studies. ${ }^{44}$ These tumors may be asymptomatic, or may present significant pain, swelling, and tenderness. Osteoblastoma-related pain may or may not be alleviated by nonsteroidal drugs or salicylates. Radiographic findings of osteoblastoma include the presence of a solitary round or oval radiolucent lesion, with foci of radiopaque structures, and a demarcated sclerotic margin. Evident radiolucent rims are seen in mature lesions with the presence of dense radiopaque structures in the center of the lesion. ${ }^{41}$ Some of these tumors could be near the apex of the root of a tooth; however, there is no relation to pulp necrosis. ${ }^{44}$ It is postulated that osteoblastomas usually have a marked growth potential and are radiographically larger than $10.5 \mathrm{~mm}$ in diameter. ${ }^{43}$ The histopathological characteristics of osteoblastoma include the presence of osteoid and bone trabeculae permeating a well-vascularized connective tissue stroma. The bone trabeculae and osteoid tissue are surrounded by a rim of plump osteoblasts with typical morphologic features. Various degrees of mineralization with evident basophilic reversal lines can be observed within the osteoid tissue. In suspected cases, mainly in enlarged and painful 
lesions, incisional biopsy is necessary for diagnosis. After histopathological confirmation, surgical treatment is recommended. The surgical treatment of osteoblastomas could vary significantly accordingly their clinical behavior and location, varying from a surgical en bloc resection, which is the treatment of choice, to aggressive curettage in cases of tumors in tooth-bearing areas ${ }^{44}$. Some aggressive cases of osteoblastomas reported presented a potential for local invasion and tend to reoccur. ${ }^{45,46}$

\section{Osteoid osteoma}

Osteoid osteoma (OO) is an uncommon benign bone tumor considered rare in the jaws. ${ }^{47}$ It occurs most frequently in the long bones, especially the proximal femur and tibia, and is usually diagnosed in the second and third decades of life, with male/female predilection at a ratio of 3 to $1 .^{48}$ In the jaws, there is a slight predilection for OO occurrence in the mandible, with just two cases occurring in a tooth-bearing area. Mohammed et al. ${ }^{47}$ reported an unusual case of $\mathrm{OO}$ associated with the apex of a mandibular second premolar and first molar. According to their report, there was a positive response of the associated teeth to the vitality tests. Tenderness and swelling may be present in craniofacial lesions, generally reaching 10-20 $\mathrm{mm}$ in size. OO presents a lower growth potential in comparison with the osteoblastoma. These lesions are usually associated with severe pain that worsens at night, at which stage relief may be obtained by non-steroidal anti-inflammatory drugs. ${ }^{44}$ There is a hypothesis that the intensity of this pain is due to the rich vascularity of $\mathrm{OO}$, which leads to innervation of the free nerve endings into the lesion, and the production of prostaglandins; this is why non-steroidal antiinflammatory drugs affecting prostaglandins could bring relief to OO-associated pain. ${ }^{49}$ Radiographically, $\mathrm{OO}$ is characterized as a round lytic lesion with a central nidus less than $10 \mathrm{~mm}$ in size, surrounded by a sclerotic bony margin. ${ }^{44}$ Although OO could resemble cemento-osseous dysplasia, a biopsy is needed for its diagnosis, when bone expansion or pain are present. ${ }^{47}$ The histological features of $\mathrm{OO}$ are very similar to those of the osteoblastoma, with the presence of osteoid, fused trabeculae within a vascularized stromal tissue, and a prominent rim of osteoblasts. Surgical excision is the treatment of choice, ${ }^{47}$ and its removal could include the affected teeth. In general, the prognosis of this condition is favorable, and recurrence is rare after surgical treatment.

\section{Cementoblastoma}

Cementoblastoma is considered a rare benign odontogenic tumor of mesenchymal/ectomesenchymal origin. This tumor affects mainly adults in the second and third decades of life, and has no apparent gender predilection. Cementoblastoma occurs in connection with the root of a tooth, mainly in mandibular permanent first molars; ${ }^{50}$ however, it may be seen in other quadrants. ${ }^{51}$ Clinically, this condition presents pain and is also associated with swelling of the buccal and lingual aspects of the alveolar ridges. Although vitality tests may indicate that the affected tooth is vital, it could present pain to percussion ${ }^{52}$. Cementoblastoma radiographically presents as a round demarcated radiopaque mass surrounded by a thin radiolucent rim connected to a tooth (Figure 3, F-G). Additionally, this lesion could be associated with root resorption, root canal invasion, tooth displacement and obliteration of the periodontal ligament space. ${ }^{50}$ Microscopically, cementoblastoma presents dense masses of acellular cementum-like material with basophilic reversal lines in a fibrous stroma. The lesion mass merges with the root of the tooth. ${ }^{16}$

Biopsy is needed for diagnosis; however, correlation with the clinical and radiographic findings are crucial to enable the correct differentiation between cementoblastoma and other mineralized tumors. Surgical excision and tooth extraction are recommended because of the fusion of the lesion to the root cementum. Cementoblastoma usually has a low risk of recurrence. ${ }^{52}$ In early diagnosis, root canal therapy and apicectomy of the involved root may be considered with the intent of saving the tooth. ${ }^{53}$

\section{Central ossifying fibroma}

Central ossifying fibroma (COF) is a benign fibro-osseous lesion of neoplastic behavior; it is composed of fibrocellular tissue and mineralized material. ${ }^{16,54} \mathrm{COF}$ arises in tooth-bearing areas, usually in the mandible, with the majority of cases presenting 
swelling and cortical expansion. Ossifying fibroma (OF) usually is not associated with pain, and some cases are detected as incidental findings during routine radiographs. ${ }^{36}$ Conventional OF usually occurs in the second and fourth decades of life, with a reported predilection for the female gender. ${ }^{16} \mathrm{COF}$ has two other variants that develop mainly in children and present a distinct histological pattern; for this reason, these variants are termed juvenile trabecular ossifying fibroma (JTOF) and juvenile psammomatoid ossifying fibroma (JPOF). ${ }^{36}$ Both variants present a predilection to occur in the craniofacial bones, especially in the paranasal sinuses and gnathic bones. In general, sinonasal presentation of juvenile OF involves an aggressive clinical behavior, rapid growth, significant bone expansion and a high tendency toward recurrence. Maxillary sinus lesions tend to extend into the paranasal sinuses and orbit, evidencing the mentioned aggressive clinical pattern of juvenile OF. Radiographic presentation of OF depends on the stage of maturity of the lesion. In an initial stage, OF may be represented radiographically by a round unilocular radiolucency with a well-defined border. Mature lesions could present a demarcated mixed radiolucent-radiopaque content, or be totally represented by a well-defined radiopaque mass. ${ }^{55}$ Cortical bone displacement, tooth displacement, and root resorption may occasionally be observed in $\mathrm{OF}^{36}$ Ramos-Perez et al. ${ }^{56}$ presented a case of OF that was very similar to chronic apical periodontitis. In their case report, the lesion was observed in conventional radiographs as a well-defined unilocular radiolucent lesion located in the apical region of an endodontically treated mandibular right canine. It was suggested that $O F$ could be considered as a differential diagnosis of unusual or persistent apical radiolucencies after adequate root canal treatment. The authors also reported that this resemblance of $\mathrm{OF}$ with apical periodontitis is very rare. ${ }^{56}$ The clinical and radiographic characteristics are essential for OF diagnosis. However, correlation between these characteristics and the histopathological presentation of the lesion must be made to ensure definite identification. Thus, biopsy is fundamental to diagnosis of $\mathrm{OF} \cdot{ }^{57}$ Histological exams of conventional OF show spindled fibroblast-like cells associated with the deposition of cementicles, osteoid and woven bone.
A prominent osteoblastic rimming is often observed adjacent to this mineralized material. Fragments of a fibrous capsule can be seen in the periphery of the pathological specimen. Curettage and enucleation are recommended in cases of conventional $\mathrm{OF}$, with low rates of recurrence reported after these surgical treatments. In juvenile OF, surgical resection may be the treatment of choice. In cases involving the sinuses, the lesions will be incompletely excised, leading to higher rates of recurrence..$^{58}$

\section{Odontoma}

Odontoma is the most common odontogenic tumor-like malformation (hamartoma) with unknown etiology that involves the tooth-bearing areas of the jaws. ${ }^{16}$ These lesions exhibit a complete differentiation of both epithelial and mesenchymal odontogenic cells, and the presence of enamel, dentin, and occasionally cementum..$^{59}$ Odontomas do not present gender predilection and are primarily detected in children and adolescents. ${ }^{16}$

Compound and complex odontomas are two different types of odontomas that can be distinguished by the level of their histologic development, and, consequently, the level of development of their mineralized content. ${ }^{59}$ Compound odontoma is represented by numerous tooth-like structures that are detected in the tooth-bearing areas of the jaws, mainly in the anterior maxilla. Complex odontoma is characterized as an amorphous calcification with dysplastic dentin covered by enamel, occurring in tooth-bearing areas, frequently in the posterior mandible. ${ }^{16,60}$ Clinically, these two types of odontomas are slow-growing conditions that rarely present clinical signs and symptoms. Odontoma of the jaw is usually an incidental radiographic finding, some cases of which are identified during the investigation into the causes of a delayed tooth eruption. ${ }^{57}$ There are some reports of bone expansion related to large odontomas, and pain and swelling related to infected odontomas. ${ }^{61,62}$ In radiographs, compound odontomas show multiple radiopaque tooth-like structures surrounded by a thin radiolucent line demonstrating a clear separation from the adjacent bone (Figure 4, A-B). The size of these lesions usually varies between 10 and $20 \mathrm{~mm}$ in diameter. Complex 
odontomas present a distinct radiographic pattern having an amorphous radiopaque structure with a fine radiopaque periphery surrounded by a radiolucent zone (Figure 4, C-D). Histologically, odontomas are composed of a capsule of connective tissue with strands or islands of odontogenic epithelium, a tubular dentin formation and an enamel matrix. ${ }^{16}$ Usually, odontomas are treated by local surgical excision, and recurrences are considered rare events. ${ }^{2}$

\section{Calcifying cystic odontogenic tumor (calcifying odontogenic cyst)}

Calcifying cystic odontogenic tumor (CCOT) is a rare benign odontogenic neoplasm that was reclassified in the last World Health Organization classification of odontogenic tumors (2005) $\cdot{ }^{16}$ CCOT was first described by Gorlin et al. in 1962, ${ }^{63}$ and hence is also known as the Gorlin cyst. This condition is identified mainly in the second and third decades of life, with no apparent gender predilection. CCOT can be found in the maxilla and mandible, with a predilection for the anterior region, ${ }^{64}$ especially in the incisor and canine regions. ${ }^{2}$ Clinically, this tumor usually is a painless, slow-growing lesion that may present bone expansion, and may be associated with an unerupted tooth, because of its occasional involvement with the crown of a tooth. In radiographic images, CCOT may be seen as a well-defined unilocular radiolucent lesion occasionally presenting as irregular radiopaque material with varying degrees of radiodensity, described as a salt and pepper pattern of flecks (Figure 4, E-F). ${ }^{64}$

In some cases, CCOT can mimic apical periodontitis, presenting as a well-defined radiolucent round lesion in the periapical region. Unlike apical periodontitis, these lesions have no relation with pulp necrosis ${ }^{65}$ but may be associated with an infected root canal. ${ }^{66}$ The multilocular appearance of CCOT was also reported; however, this is considered a very rare presentation of this tumor. ${ }^{16}$ CBCT can be an important aid in CCOT diagnosis, since the mineralized content of this tumor can be seen in CBCT exams in the periphery of the lesion. ${ }^{64}$ Biopsy is needed for CCOT diagnosis. The histopathological exam reveals a cyst wall composed of connective tissue and lined with thin odontogenic epithelial cells with ameloblastomatous features. These cells are frequently associated with
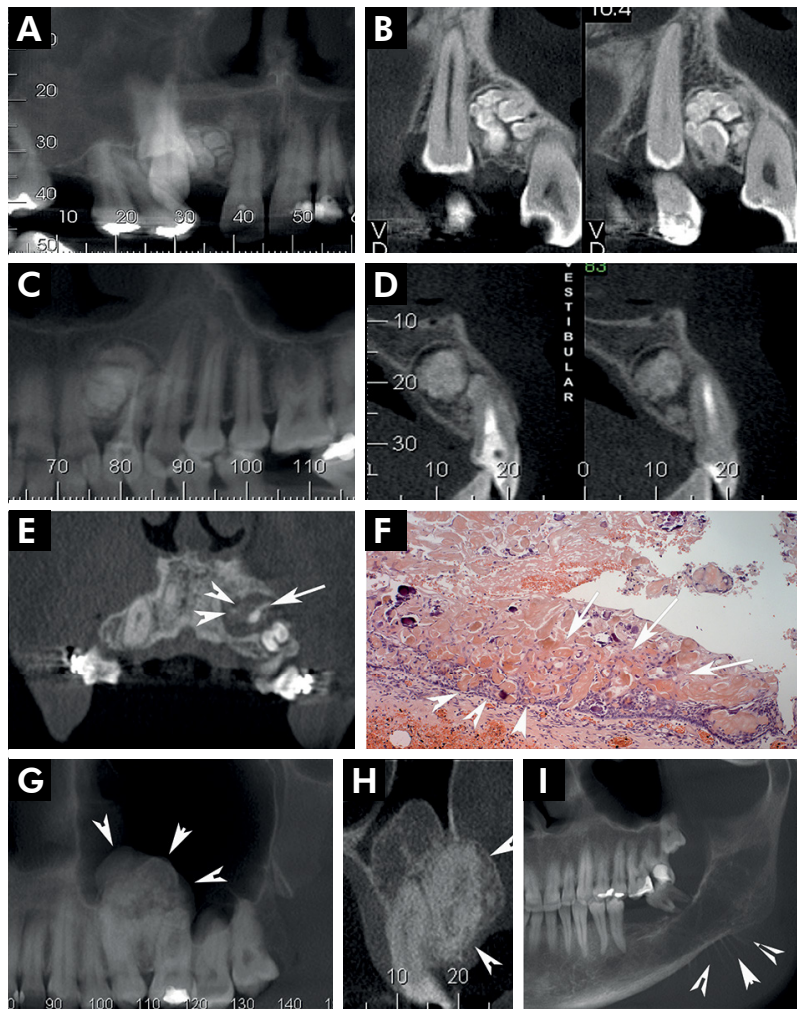

Figure 4. Compound odontoma: $\mathrm{CBCT}$ showing multiple hyperdense tooth-like structures lateral to the maxillary anterior tooth (A). Tooth-like structures presenting a fine radiolucent line that demonstrates a clear separation from the normal bone (B). Complex odontoma: Presence of a hyperdense amorphous structure with a thin radiolucent peripheral zone adjacent to the left maxillary lateral incisor (C-D). Calcifying cystic odontogenic tumor (CCOT): Coronal views showing a hypodense unilocular lesion with irregular hyperdense calcified structures in the periphery (arrowhead) and an associated odontoma (arrow) (E). Histopathological evaluation showing a cyst wall lined by ameloblastomatous odontogenic epithelia (arrowhead) associated with the formation of eosinophilic ghost cells (arrow) (F). Adenomatoid odontogenic tumor (AOT): In CBCT images, a mixed hypodense/hyperdense lesion is noted between the roots of the maxillary second premolar and first molar (arrow head) (G). In cross-sectional views, a preserved periodontal ligament space of the related tooth can be seen. There are also heterogenous calcified deposits in the lesion center (arrowhead) $(\mathrm{H})$. In a radiographic exam, a sclerotic to a mixed radiolucent/radiopaque image in posterior mandible is observed, associated with a parosteal osteogenic reaction "sunray pattern" (arrowhead) (I).

the formation of ghost cells, and, in some areas, with the presence of calcification. Eosinophilic dentinoid or dysplastic dentin can be observed in some lesions. Enucleation of CCOT is recommended. There are just a few reports of recurrence in the current literature. ${ }^{16}$ 


\section{Adenomatoid odontogenic tumor}

Adenomatoid odontogenic tumor (AOT) is a rare, benign and slow-growing odontogenic tumor composed of odontogenic epithelium. ${ }^{16}$ AOT usually is asymptomatic and identified mainly in the second decade of life, with half of the cases occurring in teenage years, and there is a slight predilection for the female gender. ${ }^{67,68}$ This tumor is associated with symptoms ranging from discrete to more obvious swelling, tooth impaction or tooth displacement. There are three clinicopathologic variants: follicular, extrafollicular and peripheral AOT (extraosseous type). The follicular type is associated with the crown of an unerupted tooth, especially a maxillary canine. The extrafollicular type may be present in the periapical region of the anterior mandible, and sometimes tooth displacement is seen. In radiographic exams, initial AOT could be a well-defined unilocular radiolucency, which could be related to the crown or be present in the interradicular region of a tooth, lateral to the root, or in the apex area, mimicking apical periodontitis. ${ }^{67,68}$ Despite the apparent similarity of this condition to apical periodontitis, AOT usually presents an intact periodontal ligament space and lamina dura, which could be a useful parameter, since inflammatory periapical lesions usually cause some periapical alterations. ${ }^{68}$ The presence of fine calcifications in the interior of the radiolucent lesion may be noted, depending on the amount of intralesional calcified deposits and the radiographic technique used (Figure 4 , G-H) $\cdot{ }^{14}$ In suspected cases, a biopsy is needed. Clinical, radiographic and histological correlation seems to benefit AOT diagnosis. Histologically, this tumor is composed of odontogenic epithelial cells with cuboidal or columnar features forming nests or rosette-like structures. Some of these tumors may be partly cystic with a solid part in the lining epithelium. Duct-like spaces, lined by a row of columnar cells with polarized nuclei, and amorphous nodules containing amyloid-like and calcified substances can be seen. Dysplastic structures or calcified osteodentin may be found in these lesions ${ }^{16}$. AOT should be treated with conservative surgical excision, and the prognosis is usually excellent. ${ }^{69}$

\section{Ameloblastic fibro-odontoma}

Ameloblastic fibro-odontoma (AFO) is a rare slow-growing benign tumor that consists of odontogenic ectomesenchyme resembling dental papilla, and that contains epithelial strands and nests that resemble dental lamina, enamel organ, dentine and enamel. ${ }^{70}$ This tumor normally affects young patients, usually between 5 and 17 years old, with no apparent gender predilection. Clinically, AFO is a painless swelling which causes a delay in tooth eruption, displacement or even tooth loosening. This tumor usually affects the posterior mandible or posterior portion of the maxilla, and could cause an evident bony expansion in these regions. ${ }^{71} \mathrm{In}$ conventional radiographs, AFO presents a well-defined radiolucent area containing variable sizes and forms of radiopaque material, affecting mainly the crown of an unerupted tooth or even the periapical region. The radiopaque material can be abundant, and AFO may be very similar to an odontoma. The diagnosis of AFO is based on histopathological specimen examination, which may reveal the presence of a cell-rich primitive ectomesenchyme resembling dental papilla, permeated cords, and nests of odontogenic epithelium with ameloblastic differentiation. The mesenchymal cells usually present a stellate or spindle-shaped appearance. Dentinoid and enamel matrix structures with different degrees of maturation can be observed in AFO specimens. ${ }^{72}$ Because of the rarity of this entity, there is no agreement about its treatment. Apparently, curettage of the involved tooth is adequate in treating small tumors. Curettage or enucleation could be indicated in treating large tumors, especially when the basal cortical bone can be preserved. Recurrence is not frequently reported. ${ }^{71}$

\section{Malignant neoplastic lesions}

\section{Osteosarcoma}

Osteosarcoma is a primary malignant bone tumor characterized by the production of osteoid or bone matrix. Osteosarcomas typically affect the long bones, with only $5 \%$ to $13 \%$ affecting the jaws. Maxilla and mandible are equally affected, with a predominance to occur in patients between the ages of 10 and 20 years, and a slight tendency to 
occur in males. ${ }^{16}$ Paparella et al. ${ }^{73}$ presented some relevant features regarding osteosarcomas of the jaw. Osteosarcomas in the maxilla and mandible tend to occur one or two decades later than osteosarcomas of the long bones, and mandibular tumors occur more frequently in the molar region. ${ }^{73}$ Clinically, these lesions are characterized by an evident swelling of the affected area, with some cases associated with pain, loosening of teeth ${ }^{16,74}$ or paresthesia. Some patients with osteosarcoma have a history of increased tumor growth after tooth extraction, ${ }^{73}$ or a history of preexisting conditions, including prior radiation, fibrous dysplasia, Paget's disease and chronic osteomyelitis. ${ }^{16}$ In radiographic exams, osteosarcoma could reveal an image that varies from sclerotic to mixed radiolucent/radiopaque (Figure 4, I), considering that the density varies according to the degree of tumor differentiation, or the stage of the disease. Recently, a case of osteosarcoma very similar to benign cementoblastoma was reported, in which there was a well-defined high-density change in the alveolar ridge surrounding the root of a mandibular molar. ${ }^{8}$ Radiographic features of osteosarcomas are quite variable, and, in the initial stage of the tumor, a widened periodontal ligament could be the only radiographic sign of the lesion; however, there are some osteosarcomas associated with the loss of visualization of the periodontal space and the destruction of the cortical plate. A sunray pattern may be seen in the osteosarcoma, which could correspond to a parosteal osteogenic reaction to the spreading of the tumor;, $, 73,74$ however, this sign is not pathognomonic. ${ }^{73}$ The variable radiographic features of the osteosarcoma make histopathological examination essential for its diagnosis. Microscopically, osteosarcomas are categorized as osteoblastic, chondroblasts and fibroblastic subtypes. Osteoblastic osteosarcoma is composed of an osteoid surrounded by irregularly arranged fibroblast-like cells. A chondroblast subtype is represented by lobules of tumor cells with a feathery appearance and atypical chondrocytes in the lacunae. In fibroblastic osteosarcoma, spindle-shaped tumor cells can be seen arranged in a herring bone pattern, and areas of osteoid formation. ${ }^{2}$ There is no consensus about the treatment protocol for osteosarcoma of the jaw, ${ }^{73}$ however, surgical resection with tumor-free margins seems to be the main modality associated with better survival rates. The benefits of radiotherapy and chemotherapy for the treatment of osteosarcoma of the jaw are still controversial. ${ }^{75}$ Overall, the survival rates are significantly higher in osteosarcoma of the jaw, in comparison with its manifestation in long bones, and distant metastases are a less frequent event.

\section{Chondrosarcoma}

Chondrosarcoma is a malignant disease with a cartilaginous formation that accounts for $10-20 \%$ of all primary malignant bone tumors, corresponding to one of the most common primary malignant bone tumors after osteosarcoma. ${ }^{76}$ Less than $1 \%$ of all chondrosarcomas affect the jaws. It is more common in males, usually in the fourth decade of life..$^{2,4}$ Clinically, chondrosarcoma of the jaw is represented by a slow-growing painless swelling that occurs most commonly in the anterior portion of the maxilla and mandible, especially in symphysis, coronoid and condylar processes. ${ }^{76}$ The radiographic characteristics of the chondrosarcoma could vary from a complete osteolytic lesion to a poorly defined radiolucent area with calcified radiopaque foci. The calcified areas may have a mottled appearance with regions of varied density. This condition usually exhibits characteristics consistent with malignancy, especially in regard to its ill-defined borders. In cases of chondrosarcoma in tooth-bearing areas, just a widened periodontal space may be seen in the initial cases, mimicking periapical inflammatory conditions, and even an osteosarcoma. ${ }^{4,76} \mathrm{CT}$ scan may be useful in evaluating tumor extension and analyzing cortical and soft tissue impairment. ${ }^{16} \mathrm{~A}$ histopathological exam is imperative for chondrosarcoma diagnosis, and a biopsy should be taken. Microscopically, conventional chondrosarcomas are classified as grade I, II or III, according to cell density and nuclear changes in neoplastic chondrocytes. These tumors are composed of round to oval cells in lacunae permeating a chondroid matrix exhibiting possible myxoid changes. Despite the histological variety of chondrosarcomas, the conventional and mesenchymal subtypes are considered most frequent in the jaws.

Mesenchymal chondrosarcomas are represented by a mixture of hyaline cartilage and small round to oval cells commonly arranged in a pericytomatous 
vascular configuration. ${ }^{16}$ Surgical resection with a wide tumor-free margin is considered the most effective treatment modality for this tumor. Radiotherapy and chemotherapy are usually used in treating high-grade cases; however, they do not seem to have any significant effect on survival rates. ${ }^{76}$

\section{Metabolism-related lesions}

\section{Renal osteodystrophy}

Renal osteodystrophy (osteitis fibrosis) is a bone pathology resulting from mineral and bone disorders from an end-stage renal disease in association with secondary hyperparathyroidism and calcitriol deficiency. These metabolic alterations give rise to a broad clinical syndrome that includes abnormalities of calcium, phosphorus, PTH and vitamin D metabolism, abnormalities in bone turnover and mineralization. Jaw involvement is relatively frequent, and reveals one of the earliest signs of the renal disease. Clinically, renal osteodystrophy is represented by a painless, diffuse or localized enlargement of the maxilla and mandible, radiographically characterized as a mixed radiolucent/radiopaque lesion, which presents an altered trabecular configuration. A diffuse ground-glass pattern and loss of lamina dura are also noted. ${ }^{77,78}$ Clinical, radiographic and histopathological findings used together are needed for renal osteodystrophy diagnosis. Histologically, this condition is composed of various-sized trabeculae of woven bone, numerous osteoblasts on the bone surface, and a great number of osteoclastic resorption lacunae. Additionally, a prominent fibrous tissue around the trabecular woven bone can be seen. Surgical recontouring is the main choice for renal osteodystrophy management. ${ }^{77}$ Parathyroidectomy has also been described as a successful modality for treating renal osteodystrophy. ${ }^{79}$

\section{Discussion}

The success of root canal treatment is determined by the absence of pain, absence or reduction of periapical lesions, and the reestablishment of tooth function. The diagnosis of periapical lesions is challenging in endodontic practice, ${ }^{1}$ because many of these lesions can mimic endodontic lesions, even when derived from different sources. ${ }^{6}$

Inflammatory changes in the periapical bone structure could be a consequence of an infection of the root canal system, and the result of osteoclastic or osteoblastic activities. These alterations are identified in radiographic exams by the presence of radiolucent or radiopaque images. ${ }^{15}$ Likewise, such bone alterations may be present in lesions of inflammatory, neoplastic, dysplastic and metabolic origin. ${ }^{8,9,10,11,77,80}$ Although radiolucent lesions are more frequently associated with root canal infection, radiopaque ones are associated with equally doubtful causes, and deserve the same attention to prevent against misdiagnosis.

Clinical aspects such pulp sensibility and vitality tests are typically helpful to determine if the periapical alterations are of inflammatory or non-inflammatory origin..$^{81}$ In this scenario, a full clinical examination, associated with the clinical and radiographic aspects of the disease, is crucial for the diagnosis of periapical lesions. Although the lack of pulp response indicates that a periapical lesion may be of endodontic origin, there are cases in which this finding may coincide with the existence of a non-endodontic lesion. In such cases, when clinical and radiographic aspects seem to be insufficient in identifying the origin of a periapical lesion, biopsy followed by histopathological examination is required.

CBCT is also an important aid in dentistry diagnosis, ${ }^{82,83,84,85}$ since it allows high accuracy in detecting periapical lesions, compared with periapical and panoramic radiography. ${ }^{85}$ The characteristics of CBCT and its map-reading strategy may enable a full examination of a multi-dimensional structure, and thus clarify the correct location of the periapical lesion, the bone resorption or bone formation characteristics, and the accuracy of the presence, absence or regression of the lesion. ${ }^{86}$

\section{Conclusion}

In summary, the endodontist must be familiarized with the diagnosis of radiolucent and radiopaque periapical lesions. Knowing how to distinguish between inflammatory and non-inflammatory lesions makes diagnosis quicker and ensures selection of the correct therapeutic regimen. 


\section{Acknowledgments}

The authors deny any conflicts of interest related to this study. This study was partially supported by

\section{References}

1. Estrela C, Holland R, Estrela CR, Alencar AH, Sousa-Neto MD, Pécora JD. Characterization of successful root canal treatment. Braz Dent J. 2014;25(1):3-11. https://doi.org/10.1590/0103-6440201302356

2. Neville BW, Damm DD, Allen CM, Chi AC. Oral and maxillofacial pathology. 4th ed. St. Louis: Elsevier; 2016.

3. Nair PNR. Biology and pathology of apical periodontitis. In: Estrela C. Endodontic science. 2nd ed. São Paulo: Artes Médicas; 2009. p. 285-347.

4. Bueno MR, De Carvalhosa AA, Castro PHS, Pereira KC, Borges FT, Estrela C. Mesenchymal chondrosarcoma mimicking apical periodontitis. J Endod 2008;34(11):1415-9. https://doi.org/10.1016/i.joen.2008.08.016

5. Bhaskar SN. Radiographic interpretation for the dentist. 3rd ed. St. Louis: Mosby; 1979.

6. Curé JK, Vattoth S, Shah R. Radiopaque jaw lesions: an approach to the differential diagnosis. Radiographics. 2012;32(7):1909-25. https://doi.org/10.1148/rg.327125003

7. Pontes FSC, Fonseca FP, Jesus AS, Alves ACG, Araújo LM, Nascimento LS et al. Nonendodontic lesions misdiagnosed as apical periodontitis lesions: series of case reports and review of literature. J Endod. 2014;40(1):16-27. https://doi.org/10.1016/i.joen.2013.08.021

8. Fang Z, Jin S, Zhang C, Wang L, He Y. Misdiagnosis of osteosarcoma as cementoblastoma from an atypical mandibular swelling: a case report. Oncol Lett. 2016;11(6):3761-5. https://doi.org/10.3892/ol.2016.4433

9. Kosti E, Lambrianidis T, Chatzisavvas P, Molyvdas I. Healing of a radiolucent periradicular lesion with periradicular radiopacity. J Endod. 2004;30(7):548-50. https://doi.org/10.1097/00004770-200407000-00020

10. Slutzky-Goldberg I, Heling I. Healing of a fibrous dysplastic lesion in a permanent molar after endodontic therapy. J Endod2007;33(3):314-7. https://doi.org/10.1016/j.joen.2006.10.016

11. Piattelli A, Perfetti G, Carraro A. Complex odontoma as a periapical and interradicular radiopacity in a primary molar. J Endod.1996;22(10):561-3. https://doi.org/10.1016/S0099-2399(96)80019-7

12. Estrela C, Porto OC, Costa NL, Garrote MS, Decurcio DA, Bueno MR et al. Large reactional osteogenesis in maxillary sinus associated with secondary root canal infection detected using cone-beam computed tomography. J Endod. 2015;41(12):2068-78. https://doi.org/10.1016/i.joen.2015.09.004 grants from the National Council for Scientific and Technological Development (CNPq, \#306394/2011-1, granted to C.E.).
13. Estrela C, Bueno MR, Leles CR, Azevedo B, Azevedo JR. Accuracy of cone beam computed tomography and panoramic and periapical radiography for detection of apical periodontitis. J Endod. 2008;34(3):273-9. https://doi.org/10.1016/i.joen.2007.11.023

14. Dare A, Yamaguchi A, Yoshiki S, Okano T. Limitation of panoramic radiography in diagnosing adenomatoid odontogenic tumors. Oral Surg Oral Med Oral Pathol. 1994;77(6):662-8. https://doi.org/10.1016/0030-4220(94)90331-X

15. Bender IB, Mori K. The radiopaque lesion: a diagnostic consideration. Endod Dent Traumatol. 1985;1 (1):2-12. https://doi.org/10.1111/j.1600-9657.1985.tb00551.x

16. Barnes L, Eveson JW, Reichart P, Sidransky D, editors. Pathology and genetics of head and neck tumours. Lyon: IARC; 2005 (World Health Organization Classification of tumours).

17. Green TL, Walton RE, Clark JM, Maixner D. Histologic examination of condensing osteitis in cadaver specimens. J Endod. 2013;39(8):977-9. https://doi.org/10.1016/i.joen.2013.02.002

18. Eversole R, Su L, ElMofty S. Benign fibro-osseous lesions of the craniofacial complex. A review. Head Neck Pathol. 2008;2(3):177-202. https://doi.org/10.1007/s12105-008-0057-2

19. Miloglu O, Yalcin E, Buyukkurt MC, Acemoglu H. The frequency and characteristics of idiopathic osteosclerosis and condensing osteitis lesions in a Turkish patient population. Med Oral Patol Oral Cir Bucal. 2009;14(12):e640-5. https://doi.org/10.4317/medoral.14.e640.

20. Prasad KC, Prasad SC, Mouli N, Agarwal S. Osteomyelitis in the head and neck. Acta Otolaryngol. 2007;127(2):194-205. https://doi.org/10.1080/00016480600818054

21. Baltensperger M, Grätz K, Bruder E, Lebeda R, Makek $M$, Eyrich $G$. Is primary chronic osteomyelitis a uniform disease? Proposal of a classification based on a retrospective analysis of patients treated in the past 30 years. J Craniomaxillofac Surg. 2004;32(1):43-50. https://doi.org/10.1016/i.jcms.2003.07.008

22. Koorbusch GF, Fotos P, Goll KT. Retrospective assessment of osteomyelitis. Etiology, demographics, risk factors, and management in 35 cases. Oral Surg Oral Med Oral Pathol. 1992;74(2):149-54. https://doi.org/10.1016/0030-4220(92)90373-X

23. Schuknecht B, Valavanis A. Osteomyelitis of the mandible. Neuroimaging Clin N Am. 2003;13(3):605-18. https://doi.org/10.1016/S1052-5149(03)00044-3 
24. Koorbusch GF, Deatherage JR, Curé JK. How can we diagnose and treat osteomyelitis of the jaws as early as possible? Oral Maxillofac Surg Clin North Am. 2011;23(4):557-67. https://doi.org/10.1016/j.coms.2011.07.011

25. Marx RE. Chronic osteomyelitis of the jaws. Oral Maxillofac Clin North Am. 1991;3(2):367-81.

26. Renapurkar S, Pasternack MS, Nielsen GP, Kaban LB. Juvenile mandibular chronic osteomyelitis: role of surgical debridement and antibiotics. J Oral Maxillofac Surg. 2016;74(7):1368-82. https://doi.org/10.1016/i.joms.2016.01.027

27. Tong AC, Ng IO, Yeung KM. Osteomyelitis with proliferative periostitis: an unusual case. Oral Surg Oral Med Oral Pathol Oral Radiol Endod .2006;102(5):e14-9. https://doi.org/10.1016/i.tripleo.2006.03.025

28. Halse A, Molven O. Idiopathic osteosclerosis of the jaws followed through a period of 20-27 years. Int Endod J. 2002;35(9):747-51. https://doi.org/10.1046/i.1365-2591.2002.00561.x

29. McDonnell D. Dense bone island. A review of 107 patients. Oral Surg Oral Med Oral Pathol. 1993;76(1):124-8. https://doi.org/10.1016/0030-4220(93)90307-P

30. Kawai T, Hirakuma H, Murakami S, Fuchihata $\mathrm{H}$. Radiographic investigation of idiopathic osteosclerosis of the jaws in Japanese dental outpatients. Oral Surg Oral Med Oral Pathol. 1992;74(2):237-42. https://doi.org/10.1016/0030-4220(92)90389-8

31. Marques Silva L, Guimaraes AL, Dilascio ML, Castro WH, Gomez RS. A rare complication of idiopathic osteosclerosis. Med Oral Patol Oral Cir Bucal 2007;12(3):E233-4.

32. Delai D, Bernardi A, Felippe GS, da Silveira Teixeira C, Felippe WT, Santos Felippe MC. Florid cemento-osseous dysplasia: a case of misdiagnosis. J Endod. 2015;41(11):1923-6. https://doi.org/10.1016/i.joen.2015.08.016

33. Summerlin DJ, Tomich CE. Focal cemento-osseous dysplasia: a clinicopathologic study of 221 cases. Oral Surg Oral Med Oral Pathol. 1994;78(5):611-20. https://doi.org/10.1016/0030-4220(94)90174-0

34. Senia ES, Sarao MS. Periapical cemento-osseous dysplasia: a case report with twelve-year follow-up and review of literature. Int Endod J. 2015;48(11):1086-99. https://doi.org/10.1111/iej.12417

35. Santos-Netto JN, Cerri JM, Miranda AM, Pires FR. Benign fibro-osseous lesions: clinicopathologic features from 143 cases diagnosed in an oral diagnosis setting. Oral Surg Oral Med Oral Pathol Oral Radiol. 2013;115(5):e56-65. https://doi.org/10.1016/j.000o.2012.05.022

36. MacDonald DS. Maxillofacial fibro-osseous lesions. Clin Radiol. 2015;70(1):25-36. https://doi.org/10.1016/i.crad.2014.06.022

37. Akintoye SO, Boyce AM, Collins MT. Dental perspectives in fibrous dysplasia and McCune-Albright syndrome. Oral Surg Oral Med Oral Pathol Oral Radiol. 2013;116(3):e149-55. https://doi.org/10.1016/i.000o.2013.05.023

38. Jour G, Oultache A, Sadowska J, Mitchell T, Healey J, Nafa K et al. GNAS Mutations in fibrous dysplasia: a comparative study of standard sequencing and locked nucleic acid PCR sequencing on decalcified and nondecalcified formalin-fixed paraffin-embedded tissues. Appl Immunohistochem Mol Morphol. 2016;24(9):660-7. https://doi.org/10.1097/PAl.0000000000000242

39. Safi Y, Valizadeh S, Vasegh S, Aghdasi MM, Shamloo N, Azizi Z. Prevalence of osteoma cutis in the maxillofacial region and classification of its radiographic pattern in cone beam CT. Dermatol Online J. 2016;22(1). pii:13030/qtlx769989.

40. Janjatov B, Erić M, Sojié D. Osteoma in medial pterygoid muscle: an unusual case. Eur Rev Med Pharmacol Sci. 2012;16(6):848-50.

41. Kaplan I, Nicolaou Z, Hatuel D, Calderon S. Solitary central osteoma of the jaws: a diagnostic dilemma. Oral Surg Oral Med Oral Pathol Oral Radiol Endod. 2008;106(3):e22-9. https://doi.org/10.1016/j.tripleo.2008.04.013

42. Bulut E, Ozan B, Günhan O. Central osteoma associated with root resorption. J Craniofac Surg. 2010;21(2):419-21. https://doi.org/10.1097/SCS.0b013e3181cfa7d7

43. Rawal YB, Angiero F, Allen CM, Kalmar JR, Sedghizadeh PP, Steinhilber AM. Gnathic osteoblastoma: clinicopathologic review of seven cases with long-term follow-up. Oral Oncol. 2006;42(2):123-30. https://doi.org/10.1016/i.oraloncology.2005.04.016

44. Jones AC, Prihoda TJ, Kacher JE, Odingo NA, Freedman PD. Osteoblastoma of the maxilla and mandible: a report of 24 cases, review of the literature, and discussion of its relationship to osteoid osteoma of the jaws. Oral Surg Oral Med Oral Pathol Oral Radiol Endod. 2006;102(5):639-50. https://doi.org/10.1016/j.tripleo.2005.09.004

45. Harrington $\mathrm{C}$, Accurso BT, Kalmar JR, Iwenofu $\mathrm{OH}$, Agrawal A, Allen CM et al. Aggressive osteoblastoma of the maxilla: a case report and review of the literature. Head Neck Pathol. 2011;5(2):165-70. https://doi.org/10.1007/s12105-010-0234-y

46. Ohkubo T, Hernandez JC, Ooya K, Krutchkoff DJ. "Aggressive" osteoblastoma of the maxilla. Oral Surg Oral Med Oral Pathol. 1989;68(1):69-73. https://doi.org/10.1016/0030-4220(89)90117-5

47. Mohammed I, Jannan NA, Elrmali A. Osteoid osteoma associated with the teeth: unusual presentation. Int J Oral Maxillofac Surg. 2013;42(2):298-302. https://doi.org/10.1016/i.ijom.2012.05.005

48. Lee EH, Shafi M, Hui JH. Osteoid osteoma: a current review. J Pediatr Orthop. 2006;26(5):695-700. https://doi.org/10.1097/01.bpo.0000233807.80046.7c

49. Liu CJ, Chang KW, Chang KM, Cheng CY. A variant of osteoid osteoma of the mandible: report of a case. J Oral Maxillofac Surg. 2002;60(2):219-21. https://doi.org/10.1053/joms.2002.29830

50. Huber AR, Folk GS. Cementoblastoma. Head Neck Pathol. 2009;3(2):133-5. https://doi.org/10.1007/s12105-008-0099-5

51. Urs AB, Singh H, Rawat G, Mohanty S, Ghosh S. Cementoblastoma solely involving maxillary primary teeth: a rare presentation. J Clin Pediatr Dent. 2016;40(2):147-51. https://doi.org/10.17796/1053-4628-40.2.147

52. Neelakandan RS, Deshpande A, Krithika C, Bhargava D. Maxillary cementoblastoma: a rarity. Oral Maxillofac Surg. 2012;16(1):119-21. https://doi.org/10.1007/s10006-011-0267-8 
53. Pacifici L, Tallarico M, Bartoli A, Ripari A, Cicconetti A. Benign cementoblastoma: a clinical case of conservative surgical treatment of the involved tooth. Minerva Stomatol. 2004;53(11-12):685-91

54. Ribeiro AC, Carlos R, Díaz KP, Gouvêa AF, Vargas PA. Bilateral central ossifying fibroma affecting the mandible: report of an uncommon case and critical review of the literature. Oral Surg Oral Med Oral Pathol Oral Radiol Endod. 2011;111(2):e21-6. https://doi.org/10.1016/j.tripleo.2010.10.024

55. Owosho AA, Hughes MA, Prasad JL, Potluri A, Branstetter B. Psammomatoid and trabecular juvenile ossifying fibroma: two distinct radiologic entities. Oral Surg Oral Med Oral Pathol Oral Radiol. 2014;118(6):732-8. https://doi.org/10.1016/i.0000.2014.09.010

56. Ramos-Perez FMM, Soares UN, Silva-Sousa YT, Perez DEC. Ossifying fibroma misdiagnosed as chronic apical periodontitis. J Endod. 2010;36(3):546-8. https://doi.org/10.1016/i.joen.2009.11.027

57. Ribeiro ACP, Carlos R, Speight PM, Hunter KD, Santos-Silva AR, Almeida $\mathrm{OP}$ et al. Peritrabecular clefting in fibrous dysplasia of the jaws: an important histopathologic feature for differentiating fibrous dysplasia from central ossifying fibroma. Oral Surg Oral Med Oral Pathol Oral Radiol. 2012;114(4):503-8. https://doi.org/10.1016/i.0ooo.2012.06.014

58. Woo SB. Central cemento-ossifying fibroma: primary odontogenic or osseous neoplasm? J Oral Maxillofac Surg. 2015;73(12 Suppl):S87-93. https://doi.org/10.1016/j.joms.2015.05.010

59. Troeltzsch M, Liedtke J, Troeltzsch V, Frankenberger R, Steiner T, Troeltzsch M. Odontoma-associated tooth impaction: accurate diagnosis with simple methods? Case report and literature review. J Oral Maxillofac Surg. 2012;70(10):e516-20. https://doi.org/10.1016/i.joms.2012.05.030

60. Sun L, Sun Z, Ma X. Multiple complex odontoma of the maxilla and the mandible. Oral Surg Oral Med Oral Pathol Oral Radiol. 2015;120(1):el1-6. https://doi.org/10.1016/i.oooo.2015.02.488

61. Vengal M, Arora H, Ghosh S, Pai KM. Large erupting complex odontoma: a case report. J Can Dent Assoc. 2007;73(2):169-73.

62. Tüzüm MS. Orofacial pain associated with an infected complex odontome. Case report. Aust Dent J. 1990;35(4):352-4. https://doi.org/10.1111/j.1834-7819.1990.tb00784.x

63. Gorlin RJ, Pindborg JJ, Odont, Clausen FP, Vickers RA. The calcifying odontogenic cyst: a possible analogue of the cutaneous calcifying epithelioma of Malherbe: an analysis of fifteen cases. Oral Surg Oral Med Oral Pathol 1962;15(1):1235-43. https://doi.org/10.1016/0030-4220(62)90159-7

64. Chindasombatjaroen J, Poomsawat S, Boonsiriseth K. Two unique cases of calcifying cystic odontogenic tumor in the maxillary posterior region. Oral Surg Oral Med Oral Pathol Oral Radiol. 2014;118(4):497-504. https://doi.org/10.1016/j.0000.2014.06.006

65. Carvalhosa AA, Estrela CRA, Borges AH, Guedes OA, Estrela C.10-year follow-up of calcifying odontogenic cyst in the periapical region of vital maxillary central incisor. J Endod. 2014;40(10):1695-7.

https://doi.org/10.1016/i.joen.2014.04.003

66. Estrela C, Decurcio DA, Silva JA, Mendonça EF, Estrela CR. Persistent apical periodontitis associated with a calcifying odontogenic cyst. Int Endod J. 2009;42(6):539-45. https://doi.org/10.1111/j.1365-2591.2008.01477.x

67. Curran AE, Miller EJ, Murrah VA. Adenomatoid odontogenic tumor presenting as periapical disease. Oral Surg Oral Med Oral Pathol Oral Radiol Endod. 1997;84(5):557-60. https://doi.org/10.1016/S1079-2104(97)90273-0

68. Philipsen HP, Srisuwan T, Reichart PA. Adenomatoid odontogenic tumor mimicking a periapical (radicular) cyst: a case report. Oral Surg Oral Med Oral Pathol Oral Radiol Endod. 2002;94(2):246-8. https://doi.org/10.1067/moe.2002.124767

69. Philipsen HP, Reichart PA, Zhang KH, Nikai H, Yu QX. Adenomatoid odontogenic tumor: biologic profile based on 499 cases. J Oral Pathol Med. 1991;20(4):149-58. https://doi.org/10.1111/j.1600-0714.1991.tb00912.x

70. Surej Kumar LK, Manuel S, Khalam SA, Venugopal K, Sivakumar TT, Issac J. Ameloblastic fibro-odontoma. Int J Surg Case Rep. 2014;5(12):1142-4. https://doi.org/10.1016/j.ijscr.2014.11.025

71. Pontes HA, Pontes FS, Lameira AG, Salim RA, Carvalho PL, Guimarães DM et al. Report of four cases of ameloblastic fibro-odontoma in mandible and discussion of the literature about the treatment. J Craniomaxillofac Surg. 2012;40(2):e59-63. https://doi.org/10.1016/i.jcms.2011.03.020

72. Martínez Martínez M, Romero CS, Piña AR, Palma Guzmán JM, Almeida OP. Pigmented ameloblastic fibro-odontoma: clinical, histological, and immunohistochemical profile. Int J Surg Pathol. 2015;23(1):52-60. https://doi.org/10.1177/1066896914553663

73. Paparella ML, Olvi LG, Brandizzi D, Keszler A, Santini-Araujo E, Cabrini RL. Osteosarcoma of the jaw: an analysis of a series of 74 cases. Histopathology. 2013;63(4):551-7. https://doi.org/10.1111/his.12191

74. Takahama Junior A, Alves FA, Pinto CA, Kowalski LP, Lopes MA. Clinicopathological and immunohistochemical analysis of twenty-five head and neck osteosarcomas. Oral Oncol. 2003;39(5):521-30.

75. Lee RJ, Arshi A, Schwartz HC, Christensen RE. Characteristics and prognostic factors of osteosarcoma of the jaws: a retrospective cohort study. JAMA Otolaryngol Head Neck Surg. 2015;141(5):470-7. https://doi.org/10.1001/jamaoto.2015.0340

76. Pontes HA, Pontes FS, Abreu MC, Carvalho PL, Kato AMB, Fonseca FP et al. Clinicopathological analysis of head and neck chondrosarcoma: three case reports and literature review. Int J Oral Maxillofac Surg 2012;41(2):203-10. https://doi.org/10.1016/i.ijom.2011.10.002

77. Lerman MA, Do C, Gunaratnam L, Kulkarni C, Tucker K, Woo SB. Localized mandibular enlargement in end-stage renal disease: two case reports and a review of the literature. Oral Surg Oral Med Oral Pathol Oral Radiol .2012;113(3):384-90. https://doi.org/10.1016/i.tripleo.2011.04.039 
78. Adachi PL, da Silva Santos PS, de Magalhães MH, Martins MT. Renal osteodystrophy manifesting as localized enlargement of the jaw. Nephrol Dial Transplant. 2007;22(8):2398-9. https://doi.org/10.1093/ndt/gfm232

79. Hata T, Irei I, Tanaka K, Nagatsuka H, Hosoda M. Macrognathia secondary to dialysis-related renal osteodystrophy treated successfully by parathyroidectomy. Int J Oral Maxillofac Surg. 2006;35(4):378-82. https://doi.org/10.1016/j.ijom.2005.08.006

80. Estrela C, Decurcio DA, Silva JA, Batista AC, Lima NCS, Silva BSF et al. Immune-inflammatory cell profile and receptor activator of nuclear factor kappa B ligand/osteoprotegerin expression in persistent apical periodontitis after root canal retreatment failure. J Endod. 2016;42(3):439-46. https://doi.org/10.1016/i.joen.2015.11.012

81. Bruno KF, Barletta FB, Felippe WT, Silva JA, Alencar AHG, Estrela $C$. Oxygen saturation in the dental pulp of permanent teeth: a critical review. J Endod. 2014;40(8):1054-7. https://doi.org/10.1016/i.joen.2014.04.01

82. Arai Y, Tammisalo E, Iwai K, Hashimoto K, Shinoda K. Development of a compact computed tomographic apparatus for dental use. Dentomaxillofac Radiol. 1999;28(4):245-8. https://doi.org/10.1038/sj.dmfr.4600448
83. Mozzo P, Procacci C, Tacconi A, Martini PT, Andreis IA. A new volumetric CT machine for dental imaging based on the cone-beam technique: preliminary results. Eur Radiol. 1998;8(9):1558-64. https://doi.org/10.1007/s003300050586

84. Cotton TP, Geisler TM, Holden DT, Schwartz SA, Schindler WG. Endodontic applications of cone-beam volumetric tomography. J Endod. 2007;33(9):1121-32. https://doi.org/10.1016/i.joen.2007.06.011

85. Estrela C, Bueno MR, Azevedo BC, Azevedo JR, Pécora JD. A new periapical index based on cone beam computed tomography. J Endod. 2008;34(11):1325-31. https://doi.org/10.1016/i.joen.2008.08.013

86. Nunes CA, Guedes OA, Alencar AH, Peters AO, Estrela CR, Estrela $C$. Evaluation of periapical lesions and their association with maxillary sinus abnormalities on cone-beam computed tomographic images. J Endod. 2016:42(1):42-46. https://doi.org/10.1016/i.joen.2015.09.014

87. Bueno MR, Estrela C, Figueiredo JAP, Azevedo BC. Map-reading strategy to diagnose root perforations near metallic intracanal posts by using cone beam computed tomography. J Endod. 2011;37(1):85-90. https://doi.org/10.1016/i.joen.2010.08.006 